\title{
UNIVERSAL EQUATION OF METAL RESISTANCE DEPENDENCE TO DEFORMATION ON CONDITIONS OF THERMOPLASTIC PROCESSING
}

\author{
${ }^{1}$ Sergey SHEYKO, ${ }^{1}$ Valerii MISHCHENKO, ${ }^{2}$ Anton MATIUKHIN, ${ }^{1}$ Olha BOLSUN, \\ ${ }^{3}$ Anton LAVRINENKOV, ${ }^{2}$ Elena KULABNEVA \\ ${ }^{1}$ Zaporizhzhia National University, Zaporizhzhia, Ukraine \\ 2 "Zaporizhzhia Polytechnic" National University, Zaporizhzhia, Ukraine \\ ${ }^{3}$ National Technical University of Ukraine "Igor Sikorsky Kyiv Polytechnic Institute", Kyiv, Ukraine, \\ sheyko.s@mail.ru, mishchen4@gmail.com,matiukhin85@gmail.com,ospodoroha@outlook.com, \\ a.lavrinenkov@kpi.ua, kulabneva.elena@gmail.com
}

https://doi.org/10.37904/metal.2021.4121

\begin{abstract}
Using finite element modelling and mathematical processing, the universal equation is obtained which establishes the dependence of the resistance of a metal to deformation on the conditions of thermoplastic processing of alloyed low pearlite steels. The finite element method is implemented in various software packages, such as Deform-2D / 3D, etc. For the correct formulation of the problem, and, consequently, the adequacy of the calculated results, in these software packages, it is necessary to set an exact description of the rheological properties of the material under study. In this regard, the availability of a mathematical model describing the rheological properties of a material for various conditions of deformation is an urgent task from a practical and scientific point of view.
\end{abstract}

Keywords: Stress-strain state, energy-power parameters, thermoplastic processing

\section{INTRODUCTION}

Deformation conditions have a significant impact on the power parameters of the process, microstructure and mechanical properties of the finished product. Deformation resistance is an important characteristic in metal forming processes (MFP) for assessing the stress-strain state, energy-power parameters. The resistance of a metal to deformation is the flow stress of the metal under static conditions of plastic deformation [1]. The flow stress characterizes the mechanical properties of the material immediately before the entrance and exit from the deformation zone, as well as in the intervals between the stands, and in the pauses between passes, during rolling, respectively, on continuous and reversing mills. Therefore, the establishment of the regularities of changes in the metal flow stress is of great importance not only for the theory of rolling, but also for technology. Therefore, the establishment of the regularities of changes in the metal flow stress is of great importance. The object of the article is to obtain the universal equation, which establishes the dependence of the resistance of metal to deformation on the conditions of thermoplastic processing of steels using experimental dependences and mathematical processing.

\section{RESEARCH METHODOLOGY}

The general view of the metal flow curve is shown in Figure 1 [2]. The dependence is characterized by an increase $\sigma_{s}(\mathrm{MPa})$ from the yield point $\sigma_{0}(\mathrm{MPa})$ to a certain peak value $\sigma_{p}(\mathrm{MPa})$ of the corresponding peak deformation $\varepsilon_{p}(-)$, after which $\sigma_{s}$ gradually decreases to the value corresponding to the steady state stress $\sigma_{y}$ $(\mathrm{MPa})$, at which an equilibrium of the processes of hardening and dynamic recrystallization occurs. It should be noted that in the section, corresponding to stresses from $\sigma_{0}$ to $\sigma_{p}$, the metal hardening rate decreases due 
to the prevalence of the dynamic recovery process over hardening. Dynamic recrystallization begins when deformation $\varepsilon_{x}(-)$ is reached. The nature of the flow curve also reflects the change in the austenite grain. In the hardening section, until the deformation value $\varepsilon_{p}$ is reached, the grains are refined, the dislocation density of the substructure increases, after which the dynamic recrystallization process develops intensively and, according to [2], the austenite grain size depends solely on stress $\sigma_{y}$.

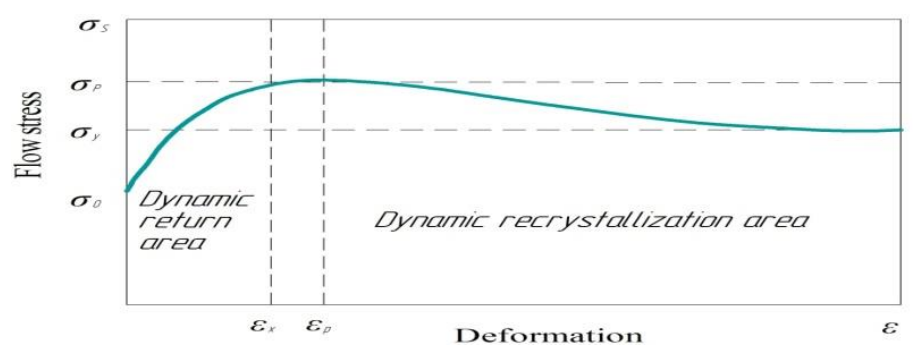

Figure 1 General view of the steel flow curve in the presence of dynamic recrystallization [2]. According to the theory of A. Nadai, the resistance of metals to deformation $\sigma_{s}$ is described by the equation [3]:

$d \sigma=\frac{\partial \sigma_{p}}{\partial T} d T+\frac{\partial \sigma_{p}}{\partial \varepsilon} d \varepsilon+\frac{\partial \sigma_{p}}{\partial \tau} d \tau+\frac{\partial \sigma_{p}}{\partial u} d u$

where:

$$
\begin{aligned}
& \sigma_{p} \text { - is the yield stress }(\mathrm{MPa}) \\
& T \text { - is the temperature }\left({ }^{\circ} \mathrm{C}\right) \\
& \mathcal{E} \text { - relative deformation }(-) \\
& T \text { - is the deformation time }(\mathrm{s}) \\
& U \text { - is the strain rate }\left(\mathrm{s}^{-1}\right) .
\end{aligned}
$$

The terms of equations (1) take into account the effect of temperature, relative deformation, softening in time, and stress changes on the resistance to deformation, taking into account the toughness of the metal.

Recently, the laws necessary for solving equations (1) have not been sufficiently studied. Therefore, in practice, to determine $\sigma_{s}$, experimental data are used in the form of specific discrete values for certain conditions of deformation and steel grades or dependences approximating experimental data [4].

The data available in the technical literature on the rate dependence of the deformation resistance of steels are often contradictory $[1,5]$ and do not always allow us to unambiguously judge the effect of one factor or another. Extensive experimental studies for various steel grades were carried out by P.M. Cook [6], A.A. Dinnik [7], V.I. Zyuzin and other authors [1,5].

There are a number of formulae for the dependence of the yield stress on the strain rate:

1. V.I. Zyuzin:

$\sigma_{p}=\sigma_{0} \cdot A_{1} \cdot A_{2} \cdot A_{3} \cdot \varepsilon^{m_{1}} \cdot u^{m_{2}} \cdot \exp \left(m_{3} T\right)$

where:
$\varepsilon$ - average degree of deformation (-)
$u$ - average rate of deformation $\left(\mathrm{s}^{-1}\right)$
$T$ - is the temperature of the environment $\left({ }^{\circ} \mathrm{C}\right)$.
$A_{1}, A_{2}, A_{3}, m_{1}, m_{2}, m_{3}$ - material constants 
2. Formula E. Siebel and A. Pomp:

$$
\sigma_{p}=\sigma_{0}+b \cdot u^{m}
$$

where:

$\sigma_{0}$ - is the yield point at static deformation (MPa)

$b$ and $u^{m}$ - are constant factors depending on the material (-).

3. Formula L.V. Andreyuk - G.G. Tyulenev:

$$
\sigma_{p}=A \sigma_{0} \cdot u^{B}(10 \varepsilon)^{C}\left(\frac{T}{1000}\right)^{D}
$$

This formula takes into account the influence of material properties, degree of deformation, strain rate and temperature, where:

$$
A, B, C, D \text { - material constants }
$$

4. Formula A. Nadai:

$$
\sigma_{p}=\sigma_{0}+m \cdot \ln \frac{u}{u_{0}}
$$

where:

$$
m \text { - is a constant coefficient depending on the material (-). }
$$

The main disadvantage of this formula is the lack of values of the coefficients included in their composition for various metals and alloys.

5. Formula A.I. Tselikov and V.A. Persiyantsev:

$$
\sigma_{p}=\sigma_{0}+D \frac{A}{u}\left(1-e^{-A \frac{\varepsilon}{u}}\right)
$$

where:

$$
\begin{aligned}
& D \text { - is the hardening modulus (MPa) } \\
& A \text { - coefficient of proportionality, which is the rate of relaxation }\left(\mathrm{s}^{-1}\right) \\
& \sigma_{0} \text { - static deformation yield stress }(\mathrm{MPa}) \\
& u \text { - average strain rate }\left(\mathrm{s}^{-1}\right) \text {. }
\end{aligned}
$$

To describe the change in the yield stress, depending on the logarithmic strain, temperature and strain rate, mathematical models are used, which are presented in works [8,9].

Expressions (2-6) in general form correctly reflect the influence of thermal and mechanical process parameters on the yield stress $\sigma_{p .}$. The yield stress is a characteristic of the rheological properties of a material. In this regard, the dependences presented above do not fully reflect the rheology of the material. They can not only grow with an increase in the degree of deformation, but also decrease or remain unchanged. In this regard, expression (7), the Hensel-Spittel formula [8] is of interest:

$$
\sigma_{p}=\alpha_{1} \varepsilon^{\alpha_{2}} \exp \left(\frac{\alpha_{3}}{\varepsilon}\right) \exp \left(\alpha_{4} \varepsilon\right)(1+\varepsilon)^{\alpha_{5} T} u^{\alpha_{6}} u^{\alpha_{7} T} T^{\alpha_{8}} \exp \left(\alpha_{9} T\right)
$$


where:
$\sigma_{p}$ - is the yield stress (MPa)
$\varepsilon$ - is the degree of deformation (-)
$u$ - is the strain rate $\left(\mathrm{s}^{-1}\right)$
$T$ - is the deformation temperature $\left({ }^{\circ} \mathrm{C}\right)$
$\alpha_{1} \ldots \alpha_{9}$ - are constant coefficients (-).

Let's analyze it. Dependencies:

$\alpha_{1} \varepsilon^{\alpha_{2}} ; \exp \left(\alpha_{4} \varepsilon\right) ;(1+\varepsilon)^{\alpha_{5} T}$,

with an increase in the degree of deformation $\varepsilon$, the yield stress $\sigma_{p}$ increases.

Dependence:

$\exp \left(\frac{\alpha_{3}}{\varepsilon}\right)$, helps to reduce the yield stress.

Dependence:

$u^{\alpha_{6}} ; u^{\alpha_{1} T}$

with an increase in the strain rate, the yield stress increases.

Dependence:

$(1+\varepsilon)^{\alpha_{T} T} ; u^{\alpha_{T} T} ; T^{\alpha_{s}} ; \exp \left(\alpha_{9} T\right)$,

can increase or decrease the yield stress, from the relationship of thermomechanical parameters.

\section{RESULTS OF THE STUDY}

As demonstrated in section 2, the Hensel-Spittel expression can describe the curve of stress dependence on thermomechanical parameters with different changes in values. The experimental data given in [10] are used to demonstrate this affirmation. The graphs in [10] show that in the case of small deformations $(\varepsilon=0.2 \ldots 0.3)$, the yield stress increases strongly with increasing deformation. At medium deformations $(\varepsilon>0.3)$, this increase in the yield point becomes less intense, and in some cases, with a further increase in deformation, it decreases.

A preliminary analysis of the mathematical models carried out above, showed that the most acceptable formula for determining the yield stress at different thermo-mechanical parameters is the above-introduce equation (7). To determine the coefficients in the formula (7) $\alpha_{1} \ldots \alpha_{9}$, you can use the experimental data presented in [10]. A system of equations is compiled, the solution of which is the indicated coefficients. For example, at $T=850$ ${ }^{\circ} \mathrm{C}, \varepsilon=0.4, u=1 \mathrm{~s}^{-1}, \sigma_{p}=225 \mathrm{MPa}$ and at $T=900^{\circ} \mathrm{C}, \varepsilon=0.6, u=10 \mathrm{~s}^{-1}, \sigma_{p}=250 \mathrm{MPa}$, etc. We get the system of equations:

1. $225=\alpha_{1} 0.4^{\alpha_{2}} \exp \left(\frac{\alpha_{3}}{0.4}\right) \exp \left(\alpha_{4} 0.4\right)(1+0.4)^{\alpha_{5} \cdot 850} 1^{\alpha_{6}}{ }^{\alpha_{7} \cdot 850} 850^{\alpha_{8}} \exp \left(\alpha_{9} 850\right)$

2. $250=\alpha_{1} 0.6^{\alpha_{2}} \exp \left(\frac{\alpha_{3}}{0.6}\right) \exp \left(\alpha_{4} 0.6\right)(1+0.6)^{\alpha_{5} \cdot 900} 10^{\alpha_{6}} 10^{\alpha_{7} \cdot 900} 900^{\alpha_{8}} \exp \left(\alpha_{9} 900\right)$

$3, \mathrm{n}$. 
This system of equations, using the method of planning the experiment, is calculated in such a way as to determine the coefficients $\alpha_{1} \ldots \alpha_{g}$. The processed experimental data, in accordance with the Reology program, made it possible to determine the coefficients $\alpha_{i}$ (Table 1 ).

Table 1 Coefficients obtained by approximation

\begin{tabular}{|c|c|c|c|c|c|c|c|c|}
\hline $\boldsymbol{\alpha}_{1}$ & $\boldsymbol{\alpha}_{\mathbf{2}}$ & $\boldsymbol{\alpha}_{\mathbf{3}}$ & $\boldsymbol{\alpha}_{\boldsymbol{4}}$ & $\boldsymbol{\alpha}_{5}$ & $\boldsymbol{\alpha}_{\boldsymbol{6}}$ & $\boldsymbol{\alpha}_{\mathbf{7}}$ & $\boldsymbol{\alpha}_{\boldsymbol{8}}$ & $\boldsymbol{\alpha}_{9}$ \\
\hline $8.2 \cdot 10^{-5}$ & $5.2 \cdot 10^{-1}$ & $-16.3 \cdot 10^{-5}$ & $1.1 \cdot 10^{0}$ & $-3.4 \cdot 10^{-3}$ & $-2.2 \cdot 10^{-1}$ & $33.6 \cdot 10^{-5}$ & $2.97 \cdot 10^{0}$ & $-4.95 \cdot 10^{-3}$ \\
\hline
\end{tabular}

Comparative curves (approximating and experimental) are represented at different temperatures, degrees and rates of deformation is shown in Figures 2, 3 [11].
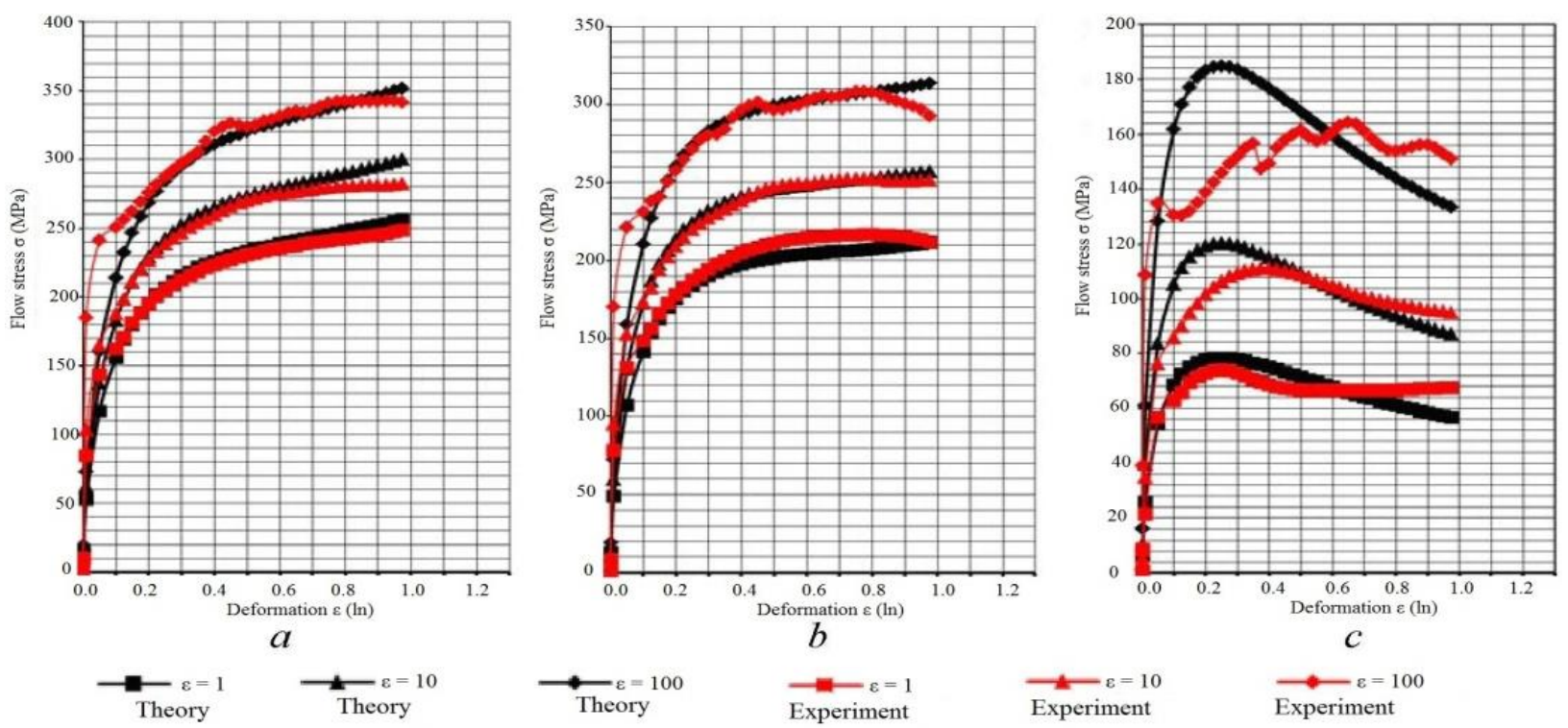

c

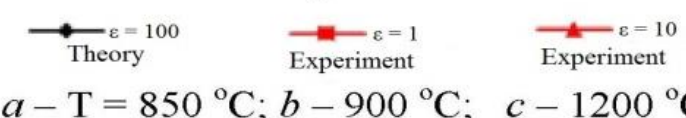

$\underset{\text { Experiment }}{\longrightarrow} \varepsilon=100$

$a-\mathrm{T}=850{ }^{\circ} \mathrm{C} ; b-900{ }^{\circ} \mathrm{C} ; \quad c-1200{ }^{\circ} \mathrm{C}$

Figure 2 Dependence of flow stress on deformation

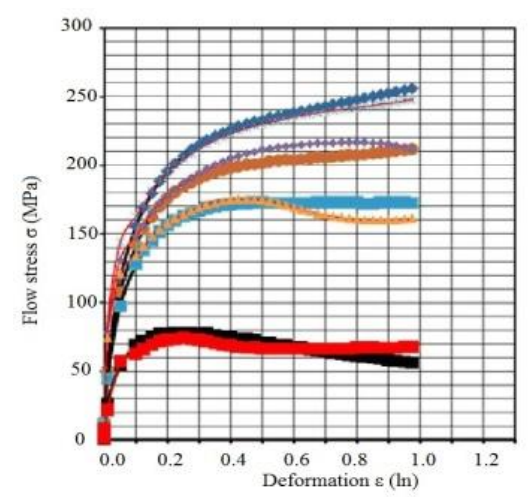

$a$

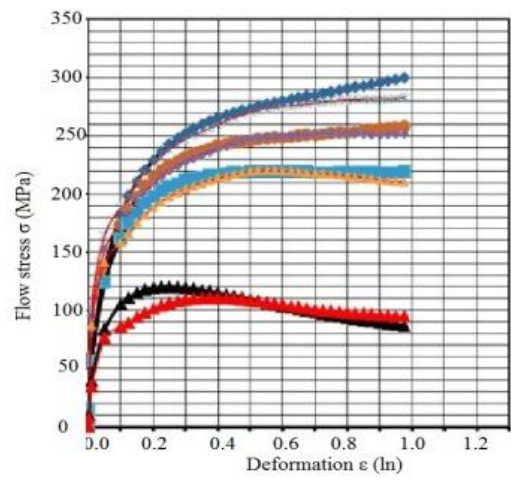

$b$

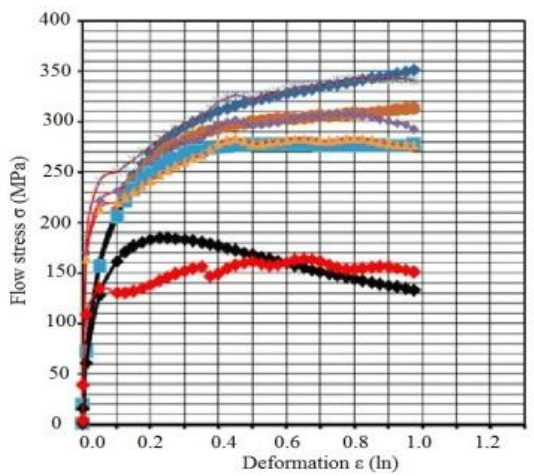

$c$

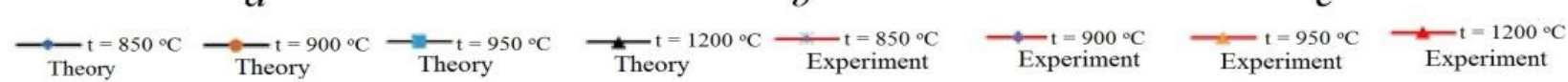

$$
\begin{aligned}
& a-u=1 \mathrm{~s}^{-1}: b-u=10 \mathrm{~s}^{-1}: c-u=100 \mathrm{~s}^{-1}:
\end{aligned}
$$

Figure 3 Dependence of flow stress on deformation

Analysis of the graphs shows the comparability of experimental and theoretical data, with the exception of the curve, at $T=1200^{\circ} \mathrm{C}$. At a strain rate $u=100 \mathrm{~s}^{-1}$, there is a significant deviation of the practical curve, from $\varepsilon$ $=0.1$ to $\varepsilon=0.5[11]$. 
Thus, a feature of this approximation is that the obtained formula can be used to take into account the rheology of various steel grades. The dependence of the yield stress on deformation can be increasing, decreasing, or not changing.

This formula can be used to calculate the energy-power parameters and the yield stress of the metal at each point of the deformation zone.

As a result of mathematical processing, an equation Mishchenko-Sheyko was obtained showing the dependence of the resistance of the metal to deformation on the conditions of thermoplastic processing:

$$
\begin{aligned}
& \sigma_{p}=0.000082 \varepsilon^{0.524152} \exp \left(\frac{-0.000163}{\varepsilon}\right) \exp (1.11363 \varepsilon)(1+\varepsilon)^{-0.003363 T} . \\
& \cdot u^{-0.216846} u^{0.000336 T} T^{2.97098} \exp (-0.004952 T) .
\end{aligned}
$$

Equation (8) allows taking into account the rheology of material properties for different conditions of deformation in comparison with the Hensel-Spittel equation.

To analyze the established patterns of changes in the resistance of the metal to deformation, three-dimensional graphical dependencies were built [11].

\section{CONCLUSION}

Thus, using the previously obtained experimental dependences in $[10,11]$ and mathematical processing, a universal equation (8) Mishchenko-Sheyko, was obtained that establishes the dependence of the resistance of the metal to deformation on the conditions of thermoplastic processing of alloyed low pearlite steels.

\section{REFERENCES}

[1] POLUHIN, P.I., GUN, G.YA., GALKIN, A.M. Soprotivlenie plasticheskoy deformatsii metallov i splavov: spravochnik. Moscow: Metallurgiya, 1983.

[2] ISHIMOV, A.S., BARYISHNIKOV, M.P., CHUKIN M.V. K voprosam vyibora matematicheskoy funktsii uravneniya sostoyaniya dlya opisaniya reologicheskih svoystv stali $20 \mathrm{v}$ protsesse goryachey plasticheskoy deformatsii. Thin Vestnik MGTU im. G.I. Nosova. 2015, vol. 1, pp. 43-52.

[3] NADAI, A. Plastichnost i razrushenie tverdyih tel. Moscow: Mir, 1969.

[4] NOVIK, F.S., ARSOV, Ya.B. Optimizatsiya protsessov tehnologii metallov metodami planirovaniya eksperimentov. Moscow: Mashinostroenie; Sofiya: Tehnika, 1980.

[5] ZYUZIN, V.I., BROVMAN, M.Ya., MELNIKOV, A.F. Soprotivlenie deformatsii staley pri goryachey prokatke. Moscow: Metallurgiya, 1964.

[6] COOK, P.M. The real cuves, stress rate of deformation for the steels by reduction. The Institution of Mechanical Engineer. 1957, pp. 75-77.

[7] DINNIK, A.A. Istinnyie predelyi tekuchesti stali pri goryachey prokatke. Thin Teoriya prokatki. 1962, pp. 157-173.

[8] HENZEL, A., SPITTEL, T. Raschet energosilovykh parametrov v processakh obrobotki metallov davlenijem. Moscow: Metallurgiya, 1982.

[9] GLOWACKI, M. Wplyw metod obliczeniowych na poprawnosc analizy procesu walcowania w wykrojach. In: Konf. Walcownictwo'99. Ustron, 1999, pp. 57-62.

[10] CHIGIRINSKIY, V. V., SHEYKO, S. P., DYJA, H., KNAPINSKI, M. Experimental and theoretical analysis of stress state of plastic medium influence on structural transformations in low-alloy steels. Thin Metallurgical and Mining Industry. 2015, vol. 11, pp.188-195.

[11] SHEYKO, S.P., MISCHENKO, V.G., BELOKON, Yu.A. Tehnologicheskie faktoryi povyisheniya mehanicheskih svoystv maloperlitnyih staley tipa 10HFTBch v proizvodstve goryachego prokata. Stal. 2021, vol. 1, pp. 62-64. 